\title{
On Cultivation of the Philosophy of College Students' Innovation
}

\author{
Xuguang Min \\ Jiangxi Science \& Technology Normal University \\ JXSTNU \\ Nanchang, China \\ minxuguang@vip.163.com \\ Xiaoqiang $\mathrm{Hu}$ \\ Jiangxi Science \& Technology Normal University \\ JXSTNU \\ Nanchang, China \\ 13870995168@163.com
}

\author{
Lisheng Yuan* \\ Jiangxi Science \& Technology Normal University \\ JXSTNU \\ Nanchang, China \\ * Corresponding Author: yls10001@qq.com \\ Fan Yang \\ Jiangxi Science \& Technology Normal University \\ JXSTNU \\ Nanchang, China \\ 771261123@qq.com
}

\begin{abstract}
This paper has discussed how to the cultivation of innovation, the new concept of innovation, how to evaluate innovation, how to foster innovation and why we need innovation for college students. It also stresses that it is valuable to teach them new ideas of innovation, make think in an innovative way, and strengthen their confidence of learning and perform innovation and finally master the theory and methods of innovation.
\end{abstract}

Keywords-college students; philosophy of innovation; evaluation of innovation; method of innovation; education

\section{INTRODUCTION}

One of the significant objectives of college education is to cultivate students' innovation capacity. However, not every university places a high value on that. Although quite a few institutions of higher education have invested more funds into their education and upgraded teaching model, their focus still remains mainly on the cultivation of students' general application competence rather than their innovation ability. And what's worse, there is even no basic education of innovation ideas, which however is the premise of the real innovation labor in the future. Therefore, the impartment of innovation ideas to college students appears to be of critical necessity. There is no denying that there are lots of related books on the market, but those especially aimed at fostering college students' innovation ability are in a relatively small volume. Apart from that, the definition of some fundamental terms about innovation in those books are unduly abstract and generalized, and there are few cases to use for reference. As a result, it is difficult to grasp the concept and approaches of innovation. So, it appears extraordinarily imperative to figure out some effective teaching methods and valuable content to enhance college students' innovation capacity with a view of college students being the major resource of future innovative talents.

\section{WHAT IS INNOVATION?}

Philosophy and information theory hold that materials are objective existence that depend not on but still can be reflected by human's consciousness. Such objective existence is what we usually call objective world, i.e. world is made of material. Information is the manifestation of the motion state and properties of all materials and knowledge is what people perceive from the information. Taking this one step further, capacity is application of knowledge and innovation is the perceiving of new knowledge , or mastering of new skills. Thus it follows that innovation derives from labour-people's conscious interaction with material world. One that is willing to or able to take part in labour dose not necessarily possess the capability of innovation. But he who is too lazy to work is absolutely doomed to possess any creativity. Universities work is also a kind of purposeful labour, and can at least lay a sound foundation for future innovation.

\section{How TO JUDGE INNOVATION}

Any meaningful activity, in a broad sense, can be categorized as a project and whether its implementation or result can be defined as innovation should be determined by the following three basic features: originality, practicability, and usability. The integration of the three features is the so-called creativity.

Firstly,originality is that your project result is authoritatively identified by legal organization to be unique and has not been publicized before by other people. Secondly, practicability is that your project result is authoritatively identified by legal organization to be of certain value in use for people and society. Thirdly, the usability amounts to operability and realizability. That is, through the authoritative evaluation of legal organization, your project result can be fully completed with little and negligible adverse effect to human and society. Of particular note is that only by matching all those three 
conditions can one project result be accredited as innovation.

Example 1, chiseling a tiny hole on the side of cup lid dose not count for innovation. Because this project has no practicability, though it shows originality( there is no cup lid having a hole on the side face so far) and usability ( easy to be achieved).

Example 2, fetching stars from the sky is not innovation. For all its originality and practicability, this project does not have usability ( can't be accomplished).

Example 3, Einstein's theory of relativity is not innovation either. In the early twentieth century, the great German scientist Einstein brought forward the relativity theory, thus expanding humans' existence from threedemensional space to four-demensional space. Its originality and practicability is self-evident, but its usability was only theoretically recognized by some world-class experts. The theory, however, cannot be put into practice at present, so the relativity theory can be merely seen as a great discovery rather than an innovation.

It is relatively easy to decide whether a project has originality or not. Once the newly-designed project is identical with an existed project on some major aspects, that project is deemed as not an innovation.

What need to be especially noted is that innovation, large or small, happens everywhere. For example, turning column-formed chalks into a shape of hexagonal prism is innovation. Because that project has the originality of being unique around the world, the practicability of preventing chalks from breaking into pieces for rolling and falling onto the ground and the usability of being easy to produce.

\section{HOW TO MAKE INNOVATIONS}

Among lots of methods of innovations, the most commonly used are combination method, substitution method, process method, disconnection approach and so on. Combination method refers to that object A and B combined in a certain way, thus yielding new properties which A and B are devoid of; Substitution means that while replacing objecting $B$, object $A$ possess the properties of $\mathrm{B}$, or even better than $\mathrm{B}$; Process method is the process of reprocessing of object $A$ and make it usable with transparent properties; While disconnection approach indicates that promote new practical properties after remove a part away from a object.

Iron and carbon, for instance, combined into different steels through different ratios, acetylene and oxygen burned with a certain proportion, producing more than three thousand degrees of temperatures, trains and rail comprise into the railway transportation system , all above listed are examples of innovation portfolio. Using engineering plastics to replace aluminum alloy doors and Windows belongs to the alternative innovation. Quenching medium carbon steel to improve the mechanical properties exponentially, belongs to the example of process innovation. Taking 3 protons from the atomic lead, the lead will turn into gold, this is an example of disconnection innovation.

These innovations are actually the basic ideas of innovation. In practice, the policy referring "imitation, improvement, experiment, amendment", is the practical methods of innovation. Many projects, before implementation, share some similar methods which can be referred to and learned, this is "imitation". Imitation can save a lot of time, manpower and financial resources. "Imitation", of course, is not applying mechanically. It is to absorb the quintessence and lead improvement on the basis of making overall understanding of the project and its advantages and disadvantages , combined with national conditions, province-circumstance and plant condition.

Taking the patrol wagon as an example, its engine, variable speed institutions, the same as some jeeps and cars, but we can enlarge its wheel diameter with several centimeters. In this way, the speed of a patrol wagon is much faster. Of course, the fuel consumption of the patrol wagon is obviously larger, because and fuel consumption is closely linked to the speed of the car, the diameter of the wheel, that is to say, it is not the bigger wheel diameter, the better it is. But the speed of patrol wagon is often more important than fuel consumption. This is an example of "improvement". Improved project should undergo testing and amendment. In this way, the innovation will be in a high growth rate, thus making results more reliable.

Besides, there exists original innovation which can solely be realized through hard work and profound summary of individual and the whole team, with no similar cases for reference and imitation. For example, China's four great inventions of the compass, papermaking, gunpowder, and typography, as well as overseas steam engine, incandescent lamp, radio, radar, laser, computer, etc., are all instances of original innovation.

\section{WHY INNOVATION IS NEEDED?}

Innovation is the soul of the national progress. It has already become a consensus that the progress of a country is completely decided by the innovative behavior of the people in that nation. At present, compared with technologically developed nations, China's science and technology level is still low. For example, in defense, Japan owned an aircraft carrier in early 20 s of last century. However, China has not truly indigenously built one yet. In the field of information technology, China still can not make a CPU (central processing unit) of microcomputer. In aerospace aspect, Americans walked on the moon in 1969. While China has just realized lunar machine landing. In the field of the agricultural production, the rice production in the United States has already accomplished mechanization, electrification, three-dimensional and green roof, while China mainly used manual way, even not realized fully irrigation. It can't stand natural disasters, such as drought, and depends much on pesticide and fertilizers.

Therefore, China is stressed a lot for catching up the world advanced level of science and technology. The great Chinese man, Mr.Mao once said, lagging behind leaves one vulnerable to attacks, and will be driven out from the earth. This "lagging behind" refers to the aspect of science and technology. College students are the important group of the national innovation talents echelon. Fostering their innovative ability has a significant meaning for the steady and rapid development of a country's material and spiritual civilization. 


\section{CONCLUSIONS}

College students are an important level of the national innovation talents echelon. Teaching them the innovative ideas is very important, such as what is the innovation, how to judge and conduct it, as well as why we should innovate and so on. It can enhance them to learn the innovation, and also provide them with their confidence and determination when they start it. In the meantime, it can better realize the value of life and contribute the strength to the construction of the national material and spiritual civilization.

\section{ACKNOWLEDGMENT}

This study was supported by the Innovation \& Startup Plan Program of College Students of Jiangxi Science \& Technology Normal University (2014-2015).

\section{REFERENCES}

[1] He Jing.Vocational College Student Cultural of Innovation Capability [D]. College of Educational of Central China Normal University, 2009, (02).

[2] Kong Ying. Cultivation of High Vocational Students Ability to Create [J]. Science \& Technology of Baotou Steel (Group) Corporation, 2006, 32(5):93-95.
[3] Min Xuguang, Xiong Zhongkan, Yang Wen. On Basic Knowledge Education and Innovative Ability Cultivation [J]. Journal of Jiangxi

Science \& Technology Normal University, 2008, (1):126-128.

[4] Qian Xuesen. A new discipline of science-The study of open complex giant system and its methodology [J]. Urban Studies, 2005, 12(5): 1-8.

[5] Zheng Kun. On Self-cultivation of Students Creativity [J]. Journal of Hebei Institute of Architectural Science \& Technology (Social Science Edition), 2004, 21(2):57-58.

[6] Liu Chuansheng. Social resposibility is the core quality of the growth the innovation talents [J] Higher Education in China, 2012, (10): 4-7.

[7] Li Hui. Platform construction of practical education of innovation in cultivation of collegiate innovative competence [J]. College Teaching in China, 2013, (9): 83-85.

[8] Qi Yeguo. On reflection of cultivation of innovative college talents in China [J]. Higher Education in China, 2012, (9): 35-37.

[9] Wang Xingang. On Instructional Methods of Cultivavtion of collegiate innovative competence [J] Research into curriculum education, 2014, (8): 246-247.

[10] Zhao Jian. Research into cultivation of collegiate venturing competence [J]. Journal of Engineering Institute of Fujian, 2010, 8 (2): 113-117. 